\title{
An Eco-friendly Synthesis, Characterization, Morphology and Ion Exchange Properties of Tercopolymer Resin derived from 2,4 dihydroxyacetophenone
}

\author{
Dr. Shailesh K. Mandavgade \\ Department of Chemistry, G. H. Raisoni Polytechnic, Nagpur-440023, India (M.S.)
}

DOI: 10.46335/IJIES.2020.5.6.1

\begin{abstract}
An effectual chelating resin was synthesized for the detoxification of harmful metal ions using a synthesized resin involving 2,4-dihydroxyacetophenone and catechol with formaldehyde (2,4-HACF-II) in 2:1:3 mol ratio using hydrochloric acid by condensation technique. The synthesized tercopolymer resin was characterized by elemental analysis, FTIR and ${ }^{1} H$ NMR spectroscopy. The average molecular weight of resin was determined by non.aqueousconductometric titration method. The physico-chemical parameters have been evaluated for the terpolymer resin. The semicrystalline nature of the synthesized tercopolymer was characterized by scanning electron microscopy (SEM). Batch equilibrium method was employed to study the selectivity and binding capacity of the tercopolymer resin toward certain metal ions such as $\mathrm{Cu}^{2+}, \mathrm{Co}^{2+}, \mathrm{Ni}^{2+}$, $\mathrm{Zn}^{2+}$ and $\mathrm{Pb}^{2+}$ in different electrolyte concentrations, wide $\mathrm{pH}$ ranges and time interverals.
\end{abstract}

Keywords-Morphology, Resin, Ion exchange, pH range and Batch equilibrium.

\section{I- INTRODUCTION}

Ion-exchange may be defined as the reversible exchange of ions between the substrate and surrounding medium. Ion exchange technique can remove traces of ion impurities from water process liquors and given out a product of ultra pure quality in a single efficient and techno economically viable manner. Ion exchangers are widely used in analytical chemistry, hydrometallurgy, antibiotics, purification and separation of radioisotopes and find large application in water treatment and pollution control [1, 2]. Lutforet. al. [3] prepared a chelating ion exchange resin containing amidoxime functional group. The chelating poly (amidoxime) resin was characterized by FT-IR spectra, TG and DSC analyses. Samir et. al. [4] synthesized ion exchange resin from 8-quinolinyl methacrylate and characterized by conventional methods. The metal ion uptake capacities of synthesized copolymers were estimated by batch equilibration method using different metal ion solutions under different experimental conditions. Three phenolformaldehyde chelating resins, poly (8hydroxyquinoline-5, 7 diylmethylene) and poly (2aminophenol-5,7diylmethylene) were synthesized and characterized by Ebraheem [5]. The chelating characteristics of these polymers were studied by a batch equilibrium technique. The ion exchange capacity, effect of electrolyte on metal ion up take, rate of metal uptake and distribution of metal ion at different $\mathrm{pH}$ with resin copolymer derived from thiosemicarbazone derivatives of phenol compound shows higher order than the resin copolymer derived from semicarbazone derivatives [6]. Recently much work has been carried out to study the ion exchange properties of anchoring functional chelating groups on the polymeric network.

The synthesized polymer resins showing versatile applications and properties attracted the attention of scientists and introduce the recent innovations in the polymer chemistry. These polymers can be used as high energy material [7], ion-exchanger [8], semiconductors [9], antioxidants [10], fire proofing agent [11], optical 
storage data [12], binders [13], molding materials, [14] etc. Pal et al. [15] has reported electrical conductivity of salicylic acid-biuret/dithio-oxamide / dithiobiurettrioxane polymer resins. Ion-exchange technique can remove traces of ionic impurities from water/process liquors and gives out a product of ultra pure quality in a simple efficient and technoeconomically viable manner.Ion-exchangers are widely used in water treatment and pollution control [16,17]. Various Hydroxybenzoic acid-formaldehyde and 4hydroxyacetophenone-biuret-formaldehyde copolymers have been reported and found to be used as ionexchangers [18,19]. The polymer resin under investigations is found to be cation exchanger having both ion-exchange group and chelating group in the same polymer matrix therefore the resin can be used selectively for the purpose of purification of waste water. One of the important applications of this chelating and functional polymer is its capability to recover metal ions from waste solution. Hence the chelating ion-exchange property of the 2,4-HACF-II polymer resin was also reported for specific metal ions.

\section{II-EXPERIMENTAL METHOD}

\section{Chemicals and reagent}

The chemicals such as 2,4-dihydroxyacetophenone and catechol were purified by rectified spirit, formaldehyde (37\%), metal chlorides and nitrates (AR grade, Merck) were used. All other solvents and the indicators were of the analytical grade procured from India. Standardized disodium salt of EDTA was used as a titrant for all the complexometric titrations.

\section{Synthesis of 2,4-HACF-II tercopolymer resin}

The 2,4-HACF tercopolymer resin was prepared by the condensation polymerization of 2,4dihydroxyacetophenone $(2.72 \mathrm{gm}, 0.2 \mathrm{~mol})$ and catechol (1.10gm, $0.1 \mathrm{~mol})$ with formaldehyde $(11.25 \mathrm{ml}, 0.3 \mathrm{~mol})$ in hydroxychloric acid medium at $126 \pm 2{ }^{\circ} \mathrm{C}$ in an oil bath for $5 \mathrm{~h}$ under refluxed condition with occasional shaking. The solid product obtained was immediately removed from the flask as soon as the reaction period was over. It was washed with cold water, dried and powdered. The powder was repeatedly washed with hot water to remove excess of 2,4-dihydroxyacetophenone-catecholformaldehyde resin, which might be present along with the 2,4-HACF-II tercopolymer resin.

The dried resin was further purified by dissolving in $8 \% \mathrm{NaOH}$ and regenerated in $1: 1(\mathrm{v} / \mathrm{v})$
$\mathrm{HCl} / \mathrm{H}_{2} \mathrm{O}$. This process was repeated twice to separate the pure polymer. The resulting polymer resin washed with boiling water and dried in vacuum at room temperature. The purified tercopolymer resin was finally ground well and kept in a vacuum over silica gel. The yield of the polymer was found to be $84 \%$ and the reaction route for the synthesis is shown in Fig. 1.<smiles>CC(=O)c1ccc(O)cc1O</smiles>

2,4-Dihydroxyacetophenone Catechol Formaldehyde

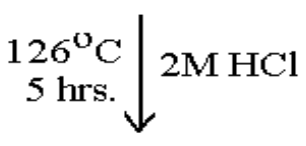<smiles>CC(=O)c1cc(Cc2ccc(Cc3cc(C(C)(C)C)c(O)c(CC(C)(C)C)c3O)c(O)c2O)c(O)c(C(C)=O)c1</smiles>

Fig. 1 Formation of 2,4-HACF Tercopolymer Resin

\section{III- CHARACTERIZATION OF TERCOPOLYMER RESIN}

\section{Physicochemical and elemental analysis}

The tercopolymer resin was subject to micro analysis for $\mathrm{C}, \mathrm{H}$ and $\mathrm{N}$ on an ElementerVario EL III Carlo Ebra 1108 elemental analyzer. The number average molecular weight $(\overline{\mathrm{Mn}})$ was determined by conductometric titration in DMSO medium using ethanolic $\mathrm{KOH}$ as the titrant by using $25 \mathrm{mg}$ of sample. A plot of the specific conductance against the milliequivalents of $\mathrm{KOH}$ requires for neutralization of $100 \mathrm{~g}$ of polymer was made. Inspection of such a plot revealed that there were many breaks in the plot. From this plot, The first break and the last break were noted. The calculation of $(\overline{\mathrm{Mn}})$ by this method is based on the following consideration. On the basis of average degree of polymeration, $\overline{\mathrm{DP}}$ the average molecular weight has to be determined by following equation. 


\author{
Total meq.of base required for \\ completeneutralization \\ $\overline{\mathrm{DP}}$ \\ Meq.of base required for smallest interval$$
\mathrm{Mn}=\mathrm{DP} \times \mathrm{Repeat} \text { unit weight. }
$$

The intrinsic viscosity was determined using a TuanFuoss viscometer [20] at six different concentrations ranging from 0.3 to $0.05 \mathrm{wt} \%$ of resin in DMF at $30^{\circ} \mathrm{C}$. Intrinsic viscosity (n) was calculated by the Huggin's equation [21] and Kraemer's equation. [22].

$$
\begin{aligned}
& {\left[\eta_{\mathrm{sp}} / \mathrm{c}\right]=[\eta]+\mathrm{K}_{1}[\eta]^{2} \cdot \mathrm{C}} \\
& \operatorname{In}\left[\eta_{\mathrm{r}} / \mathrm{c}\right]=[\eta]-\mathrm{K}_{2}[\eta]^{2} \cdot \mathrm{C}
\end{aligned}
$$

\section{Spectral Analysis}

Electron absorption spectra of tercopolymer (2,4-HACFII) were recorded in 200 to $800 \mathrm{~nm}$ range by using Shimadzu automatic recording double beam spectrophotometer (UV-VIS-NIR Spectrometer) UV-240 at Sophisticated Analytical Instrument Facility, Punjab University, Chandigarh having $10 \mathrm{~nm}$ optical path supplied with the instruments were used. An infra-red spectrum of 2,4-HACF-II polymer resin was recorded in the region 4000 to $400 \mathrm{~cm}^{-1}$ were scanned in $\mathrm{KBr}$ pellet on Perkin Elmer Model 983 spectrophotometer at Sophosticated Analytical Instrument Facility, Panjab University, Chandigarh.A Nuclear Magnetic Resonance $\left({ }^{1} \mathrm{H}\right.$ NMR) spectrum of newly synthesized polymer resin has been scanned on $90 \mathrm{MHz}$ for proton using BrukerAvance II 400 NMR Sepctrometer in deuterated dimethyl sulphoxide (DMSO-d $)_{6}$ at Sophisticated Analytical Instrumentation Facility, Panjab University, Chandigarh. Scanning electron micrograph of polymer has been scanned and magnification by scanning electron microscope at Sophisticated Test and Instrumentation Centre, STIC, Cochin University, Cochin.

\section{Ion-exchange properties}

The ion-exchange property of the 2,4-HACF-II terpolymer resin was determined at three different variations given below.

Determination of metal uptake in the presence of electrolytes of different concentrations

The 2,4-HACF terpolymer ( $25 \mathrm{mg}$ ) was taken in a precleaned glass bottles and each of the electrolytes (25 mL) such as $\mathrm{NaClO}_{4}, \mathrm{NaCl}, \mathrm{Na}_{2} \mathrm{SO}_{4}$ and $\mathrm{NaNO}_{3}$ in different concentrations viz. 0.01, 0.1 and $0.5 \mathrm{M}$. The $\mathrm{pH}$ of the suspension was adjusted to the required value either by adding $0.1 \mathrm{M} \mathrm{HCl}$ or $0.1 \mathrm{M} \mathrm{NaOH}$ and mechanically stirred for $24 \mathrm{~h}$ at $25^{\circ} \mathrm{C}$ for swelling of the terpolymer. Then exactly $0.1 \mathrm{M}$ of the metal ion solution $(2 \mathrm{~mL})$ was added and vigorously stirred for $24 \mathrm{~h}$ at room temperature. The mixture was then filtered off and washed with distilled water. The filtrate and the washings were collected and then the amount of metal ion adsorbed was estimated by titrating against standard Na2EDTA solution. A blank experiment was also performed following the same procedure without the polymer sample. The amount of metal ions taken up by the polymer in the presence of a given electrolyte can be calculated from the difference between the actual value and that of from the blank.

\section{Evaluation of the Distribution of Metal Ions at Different pH}

The distribution of each of the metal ions at various $\mathrm{pH}$ ranging from 1.5 to 6 between the polymer phase and the aqueous phase were determined in the presence of $1 \mathrm{M}$ $\mathrm{KNO} 3$ at $25^{\circ} \mathrm{C}$. The distribution ratio $\mathrm{D}$, may be defined as

$\mathrm{D}=$ Weight (in $\mathrm{mg}$ ) of metal ions taken up by $1 \mathrm{~g}$ of the resin sample / Weight (in $\mathrm{mg}$ ) of metal ions present in 1 $\mathrm{mL}$ of the solution.

\section{Evaluation of Rate of Metal Ion Uptake}

The time required for attaining the state of equilibrium under the experimental conditions was evaluated by a series of experiments carried out to determine the amount of metal ion adsorbed by the terpolymer at specific time intervals. $25 \mathrm{mg}$ of the polymer sample was mechanically stirred with $25 \mathrm{~mL}$ of $1 \mathrm{M} \mathrm{KNO} 3$ to allow the polymer to swell. The $\mathrm{pH}$ of the suspension was adjusted to the required value by adding either $0.1 \mathrm{M}$ $\mathrm{HCl}$ or $0.1 \mathrm{M} \mathrm{NaOH}$. It was observed that under the given experimental conditions the state of equilibrium established within $24 \mathrm{~h}$ at $25^{\circ} \mathrm{C}$. The rate of metal ion uptake is expressed as the percentage of the metal ion uptake after the specific time related to the state of equilibrium. It is given as,

Metal ion uptake $=$ Amount of metal ion adsorbed / Amount of metal ion adsorbed at equilibrium $\times 100$

\section{IV- RESULTS AND DISCUSSION}

The resin sample was dark brown in color and soluble in solvents like N,N-dimethylformamide (DMF), 
tetrahydrofuran (THF), dimethylsulphoxide (DMSO), aqueous sodium and potassium hydroxide solutions and insoluble in alcohol, chloroform and carbon tetrachloride. The melting point of resin is $499 \mathrm{~K}$ and empirical formula of the terpolymer resin is found to be $\mathrm{C}_{25} \mathrm{H}_{22} \mathrm{O}_{8}$ which is in good agrrement with the calculatedvalues of $\mathrm{C}, \mathrm{H}$ and $\mathrm{O}$. The molecular weight of terpolymer resin was also determined by conductometric titration. The calculated molecular weight for $2,4-\mathrm{HACF}$ resin is 3600 .

\section{Electronic Spectral Analysis}

The UV-Visible spectra of the 2,4-HACF tecorpolymer resin in pure DMF were recorded in the region 200-800 $\mathrm{nm}$. The spectra have shown in Fig 2. The UV-Visible spectra of 2,4-HACF tercopolymer resin gave rise to two characteristic bands at about 230 to $270 \mathrm{~nm}$ and 310 to $370 \mathrm{~nm}$. This observed positions for the absorption bands clearly indicate the presence of carbonyl group in the sample belonging to 2,4-dihydroxyacetophenone moiety. The former band (more intense) appeared as a result of $\pi \rightarrow \pi^{*}[23]$ transition while the latter band (less intense) may be due to $n \rightarrow \pi^{*}$ [24] electronic transition.

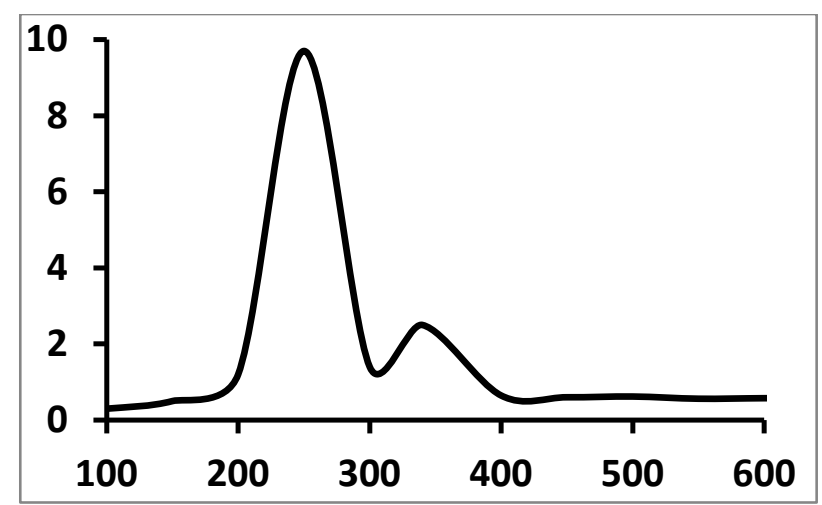

Fig. 2 Electronic spectra of 2,4-HACF tercopolymer resin

\section{Infra-Red Spectral Analysis}

The IR spectra of 2,4-HACF tercopolymer resin are presented in Fig. 3. A broad band appeared in the 3287 (b) $\mathrm{cm}^{-1}$ may be assigned to the stretching vibration of phenolic hydroxyl (-OH) group exhibiting intermolecular hydrogen bonding [25]. The sharp and weak band obtained at $1284(\mathrm{w}) \mathrm{cm}^{-1}$ suggest the presence of $\mathrm{Ar}-\mathrm{CH}_{2}-\mathrm{Ar}$ bridge in polymer. The sharp strong peak at $1435(\mathrm{~s}) \mathrm{cm}^{-1}$ may be ascribed to aromatic skeletal ring [25]. The bands obtained at $1371 \mathrm{~cm}^{-1}$ suggest the presence of methylene $\left(-\mathrm{CH}_{2}\right)$ bridge [26]. The sharp band displayed at $1624 \mathrm{~cm}^{-1}$ may be due to stretching vibration of carbonyl group attached to acetophenonemoity. The 1,2,3,5 substitution of aromatic benzene ring recognized by the sharp, medium / weak absorption and appeared at 562(st), 800(s), 986(s) and $1072(\mathrm{~m}) \mathrm{cm}^{-1}$ respectively. This band seems to be merged with very broad band of phenolic hydroxyl group [25,26].

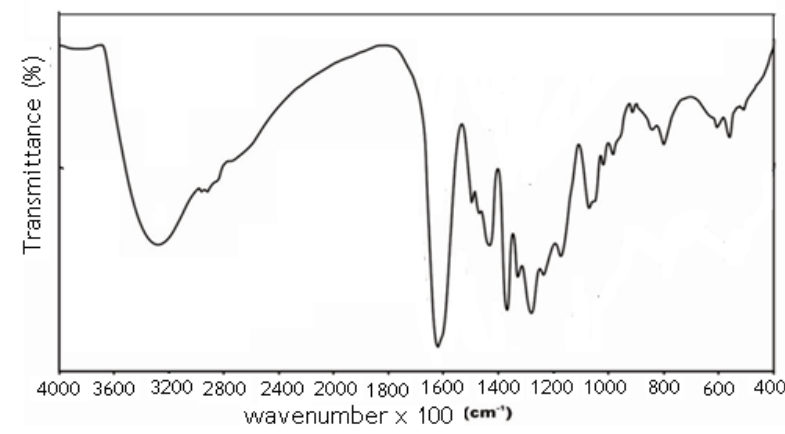

Fig. 3 Infra-red spectra of 2,4-HACF tercopolymer resin

\section{${ }^{1}$ H NMR Spectral Analysis}

The NMR spectra of 2,4-HACF is presented in Fig. 4. The singlet obtained in the region $2.26(\delta)$ ppm may be due to the methylene proton of $\mathrm{Ar}-\mathrm{CH}_{2}-\mathrm{Ar}$ bridge [27]. The weak multiple signals (unsymmetrical pattern) in the region of $7.71(\delta)$ ppm may be attributed to aromatic proton $(\mathrm{Ar}-\mathrm{H})$ [28]. The signals in the $8.19(\delta)$ ppm may be due to phenolic hydroxyl protons. The much downfield chemical shift for phenolic-OH indicates clearly the intramolecular hydrogen bonding of -OH group [29]. The signal appeared in the region at $6.32(\delta)$ ppm is due to the methylene proton of $\mathrm{Ar}-\mathrm{CH}_{2}$ bridge [30]. The methyl protons of the $\mathrm{Ar}-\mathrm{CO}-\mathrm{CH}_{3}$ moiety may be identified by the intense peak at $3.28(\delta)$ ppm.

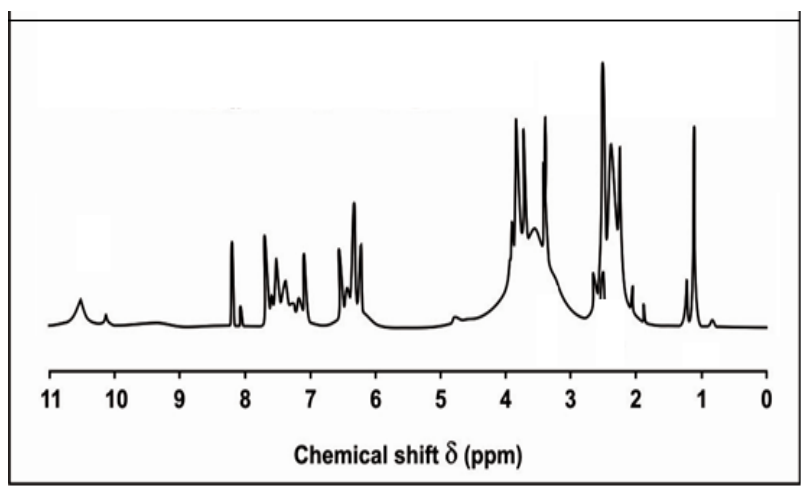

Fig. $4{ }^{1} \mathrm{H}$ NMR spectra of 2,4-HACF tercopolymer resin

\section{Scanning electron microscopy (SEM)}

The scanning electron micrograph of 2,4-HACF-II tercopolymer resin have been scanned and magnification 
by analytical scanning electron microscope at Sophisticated Test and Instrumentation Centre, STIC, Cochin University, Cochin as shown in the Fig.5. Surface analysis has found great use in understanding the surface features of the polymers. SEM gives the information of surface topology and defect in the structure. The semi crystalline nature of 2,4-HACF-II tercopolymer resin was established by scanning electron microscopy. The morphology of resin sample thus identified by SEM as crystalline as well as amorphous or transition between crystalline and amorphous, showing more or less good ion capacity. The polymerization reaction proceeds by introducing amorphous character in the tercopolymer sample.

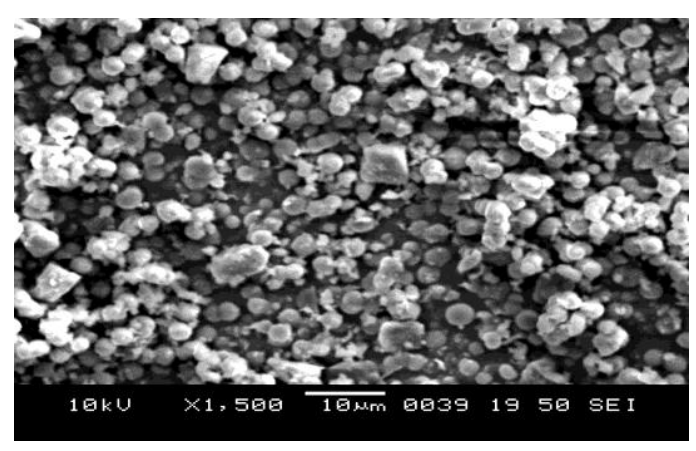

Fig. 5 Scanning electron microscopy of 2,4-HACF TercopolymerResin

\section{Ion-exchange properties}

Batch equilibrium technique developed by De Geiso et al. [31] and Gregor et al. [32]was used to study ionexchange properties of 2,4-HACF-II polymer resin. The results of the batch equilibrium study carried outwith the polymer 2,4-HACF-II are presented in Tables $1-3$. Five metal ions $\mathrm{Cu}^{2+}, \mathrm{Ni}^{2+}, \mathrm{Co}^{2+}, \mathrm{Zn}^{2+}$ and $\mathrm{Pb}^{2+}$ in the form of aqueous metal nitrate solution were used. The ionexchange study was carried out using three experimental variables such as a) electrolyte and its ionic strength b) uptake time and c) $\mathrm{pH}$ of the aqueous medium

\section{Effect of Electrolytes on Metal Ion Uptake}

Generally as concentration increases of the electrolyte, the ionization decreases, the number of ligands decreases in the solution which form the complex with less metal ions and more ions are available for adsorption. The variable metal ions uptake capacity of 2,4-HACF tercopolymer resin may be due to the strong and weak complex formation between electrolyte ligands and metal ions. Examination of the data given in Table 1 reveals that the amount of metal ions taken up from a given amount of tercopolymers depends on the nature and concentration of the electrolyte present in the solution. In presence of perchlorate, chloride and nitrate ions, the uptake of $\mathrm{Cu}^{2+}$ and $\mathrm{Ni}^{2+}$ ions increases with increasing concentration of the electrolytes, whereas in presence of sulphate ions the amount of the above mentioned ions taken up by the tercopolymers decreases with increasing concentration of the electrolytes [33]. Moreover, the amount of $\mathrm{Co}^{2+}, \mathrm{Zn}^{2+}$ and $\mathrm{Pb}^{2+}$ ions taken up by the tercopolymer samples decreases with increasing concentration of the chloride, nitrate, perchlorate and sulphate ions [33]. This may be explained in terms of the stability constants of the complexes which $\mathrm{Cu}^{2+}, \mathrm{Ni}^{2+}, \mathrm{Co}^{2+}, \mathrm{Zn}^{2+}$ and $\mathrm{Pb}^{2+}$ ions from with these anions. $\mathrm{SO}_{4}{ }^{2-}$ might form rather strong complexes with $\mathrm{Ni}^{2+}$ and $\mathrm{Cu}^{2+}$ ions, while $\mathrm{ClO}_{4}^{-}, \mathrm{NO}_{3}^{-}$ and $\mathrm{Cl}^{-}$might form weak complexes and, therefore, might not be expected to influence the position of the $\mathrm{Ni}^{2+}$ and $\mathrm{Cu}^{2+}$ chelates equilibrium as much as $\mathrm{SO}_{4}{ }^{2-}$ Sulphate, perchlorate, nitrate and chloride might form rather strong chelates with $\mathrm{Co}^{2+}, \mathrm{Zn}^{2+}$ and $\mathrm{Pb}^{2+}$ and therefore might be expected to influence the position of the $\mathrm{Co}^{2+}, \mathrm{Zn}^{2+}$ and $\mathrm{Pb}^{2+}$ chelates equilibrium.

Table 1.Evaluation of the uptake of metal ions by 2,4HACF-II resin

\begin{tabular}{|c|c|c|c|c|c|}
\hline \multirow{6}{*}{$\begin{array}{c}\text { Metal } \\
\text { ions }\end{array}$} & \multirow{2}{*}{$\begin{array}{c}\begin{array}{c}\text { Concentrati } \\
\text { on of } \\
\text { electrolytes } \\
(\mathrm{mol} / \mathrm{L})\end{array} \\
0.01\end{array}$} & \multicolumn{4}{|c|}{$\begin{array}{l}\text { Weight of metal ion uptake in } \\
\text { presence of electrolytes (mg) }\end{array}$} \\
\hline & & 2.25 & 2.54 & 2.42 & 3.59 \\
\hline & 0.05 & 2.67 & 2.87 & 2.54 & 2.78 \\
\hline & 0.10 & 2.94 & 3.11 & 2.79 & 2.11 \\
\hline & 0.50 & 3.23 & 3.42 & 3.46 & 1.45 \\
\hline & 1.00 & 3.32 & 3.78 & 3.54 & 0.83 \\
\hline \multirow{5}{*}{$\mathrm{Ni}^{2+}$} & 0.01 & 1.56 & 1.19 & 1.32 & 2.78 \\
\hline & 0.05 & 2.13 & 1.32 & 1.67 & 2.04 \\
\hline & 0.10 & 2.96 & 1.44 & 2.03 & 1.45 \\
\hline & 0.50 & 3.43 & 1.67 & 2.23 & 0.89 \\
\hline & 1.00 & 4.11 & 2.36 & 2.56 & 0.52 \\
\hline \multirow{5}{*}{$\mathrm{Co}^{2+}$} & 0.01 & 1.59 & 1.63 & 1.95 & 1.65 \\
\hline & 0.05 & 1.42 & 1.39 & 1.72 & 1.38 \\
\hline & 0.10 & 1.18 & 1.18 & 1.49 & 1.27 \\
\hline & 0.50 & 0.84 & 0.92 & 1.11 & 1.11 \\
\hline & 1.00 & 0.47 & 0.57 & 0.72 & 0.82 \\
\hline \multirow{5}{*}{$\mathrm{Zn}^{2+}$} & 0.01 & 1.75 & 1.66 & 2.39 & 1.89 \\
\hline & 0.05 & 1.52 & 1.38 & 2.07 & 1.52 \\
\hline & 0.10 & 1.24 & 1.17 & 1.67 & 1.21 \\
\hline & 0.50 & 0.92 & 0.93 & 1.24 & 1.17 \\
\hline & 1.00 & 0.67 & 0.69 & 0.75 & 0.81 \\
\hline \multirow{5}{*}{$\mathrm{Pb}^{2+}$} & 0.01 & 1.46 & 1.68 & 1.83 & 1.92 \\
\hline & 0.05 & 1.29 & 1.43 & 1.69 & 1.64 \\
\hline & 0.10 & 1.17 & 1.17 & 1.34 & 1.32 \\
\hline & 0.50 & 1.03 & 0.91 & 1.12 & 1.03 \\
\hline & 1.00 & 0.82 & 0.58 & 0.68 & 0.75 \\
\hline
\end{tabular}




\section{Evaluation of the Rate of Metal Ion Uptake}

The data of metal ion uptake at various shaking time intervals is given in Table 2. These results indicate that the time taken for the uptake of the different metal ions at a given stage depends on the nature of metal ion under given conditions. It is found that $\mathrm{Cu}^{2+}, \mathrm{Ni}^{2+}, \mathrm{Co}^{2+}$ and $\mathrm{Zn}^{2+}$ ions require about $5 \mathrm{~h}$ for the establishment of the equilibrium where as $\mathrm{Pb}^{2+}$ ions required almost $6 \mathrm{~h}$ for equilibrium. Thus, the rate of metal ion uptake follows the order $\mathrm{Cu}^{2+}, \mathrm{Ni}^{2+}, \mathrm{Co}^{2+}, \mathrm{Zn}^{2+}>\mathrm{Pb}^{2+}$ for all the tercopolymers. The trend is good agreement with earlier workers [34, 35].

Table 2 Evaluation of rate metal ion uptake by 2,4HACF-II resin

\begin{tabular}{|c|c|c|c|c|c|c|}
\hline \multirow{2}{*}{$\begin{array}{c}\text { Metal } \\
\text { ions }\end{array}$} & \multicolumn{6}{|c|}{ Equilibrium attainment (\%) } \\
\cline { 2 - 7 } & \multicolumn{7}{|c|}{ Time (h) } \\
\cline { 2 - 7 } & 1 & 2 & 3 & 4 & 5 & 6 \\
\hline \multirow{2}{*}{$\mathrm{Cu}^{2+}$} & 62.6 & 72.7 & 81.4 & 86.3 & 94.1 & - \\
$\mathrm{Ni}^{2+}$ & 69.4 & 75.3 & 83.3 & 89.4 & 95.3 & - \\
$\mathrm{Co}^{2+}$ & 47.4 & 63.4 & 77.3 & 85.5 & 95.9 & - \\
$\mathrm{Zn}^{2+}$ & 53.2 & 63.2 & 72.2 & 85.3 & 94.2 & - \\
$\mathrm{Pb}^{2+}$ & 32.4 & 49.1 & 65.2 & 75.1 & 85.4 & 95.2 \\
& & & & & & \\
\hline
\end{tabular}

\section{Distribution Ratio of Metal Ions at Different pH}

The effect of $\mathrm{pH}$ on the amount of metal ion distributed between two phases can be explained by the result shown in the Table 3. The result indicate that the relative amount of metal ion adsorbed by the tercopolymer resin increase with increasing $\mathrm{pH}$ of the medium. The study was carried out up to definite $\mathrm{pH}$ value for the particular metal ion to prevent hydrolysis of the metal ions at higher $\mathrm{pH} . \mathrm{Cu}^{2+}$ and $\mathrm{Ni}^{2+}$ have highest distribution ratio at $\mathrm{pH} 2.5$ to 6 , therefore these ions can be taken up more selectively between the ranges of $\mathrm{pH}$ 2.5-6. The other three ions $\mathrm{Co}^{2+}, \mathrm{Zn}^{2+}$ and $\mathrm{Pb}^{2+}$ have lower distribution ratio over $\mathrm{pH}$ range of 2.5 to 6 . The high distribution ratio may be due to higher stability constant of metal ligand complexes and vice versa. $\mathrm{Cu}^{2+}$ and $\mathrm{Ni}^{2+}$ may form more stable complex, indicate that these ions adsorbed more selectively to the higher extent, rather than $\mathrm{Co}^{2+}, \mathrm{Zn}^{2+}$ and $\mathrm{Pb}^{2+}$ which may form rather weak complexes with ligand during the course of time, therefore these ions adsorb to a least extent over an entire $\mathrm{pH}$ range study [36]. Thus, the order of selectivity of metal ions by all the terpolymer is found to be $\mathrm{Cu}$ (II) $>\mathrm{Ni}$ (II) $>\mathrm{Co}$ (II) $>\mathrm{Zn}$ (II) $>\mathrm{Pb}$ (II). The results are in good agreement with earlier co-workers [36]. Hence, the results of this type of study are helpful in selecting the optima $\mathrm{pH}$ for a selective uptake of a metal ion from a mixture of different ion.

Table 3 Evaluation of distribution ratio D, at different $\mathrm{pH}$

\begin{tabular}{|c|c|c|c|c|c|c|c|c|}
\hline \multirow{2}{*}{$\begin{array}{c}\text { Meta } \\
1\end{array}$} & \multicolumn{7}{|c|}{ Distribution ratio(KD) of the metal ions } \\
\cline { 2 - 8 } ions & 1.5 & 2 & 2.5 & 3 & 3.5 & 4 & 5 & 6 \\
\cline { 2 - 8 } & \multicolumn{7}{|c|}{$\mathrm{pH}$ of the medium } \\
$\mathrm{Cu}^{2+}$ & - & - & 74.8 & 92.5 & 212.3 & 489.7 & 865.4 & 1134.4 \\
$\mathrm{Ni}^{2+}$ & - & - & 63.4 & 79.3 & 145.3 & 356.1 & 567.1 & 874.3 \\
$\mathrm{Co}^{2+}$ & - & - & 48.2 & 57.4 & 93.4 & 143.1 & 268.5 & 453.3 \\
$\mathrm{Zn}^{2+}$ & - & - & 57.4 & 62.4 & 89.3 & 165.5 & 244.6 & 343.2 \\
$\mathrm{~Pb}^{2+}$ & - & - & 42.4 & 62.4 & 79.8 & 112.3 & 156.2 & 278.4 \\
& & & & & & & & \\
\hline
\end{tabular}

\section{V-CONCLUSION}

A tercopolymer 2,4-HACF-II based on the condensation reaction of 2,4dihydroxyacetophenone and catechol with formaldehyde in the presence of acid catalyst was prepared. The 2,4-HACF-II resin is a selective chelating cation exchange terpolymer resin for certain metals. The uptake capacities of metal ions by the polymer resin were $\mathrm{pH}$ dependent. The uptake capacities of metal ions by the tercopolymer resin were carried out by batch equilibrium technique. Due to the considerable difference in the adsorption capacity at different $\mathrm{pH}$ media, the rate of metal uptake and distribution ratio at equilibrium, it may be possible to use the tercopolymer for separation of particular metal ions. Also from the FTIR and ${ }^{1} \mathrm{H}$ NMR spectral studies the proposed structure of the 2,4-HACF-II polymer resin has been determined.

\section{REFERENCES}

[1] Kunin $R$ (1958) Ion Exchange Resins, 3rd Ed Wiley New York

[2] Lutfor MR and Silong S (2000)EurPolym J 36: 2105

[3] Patel SA, Shah BS and Patel RM (2004), Iran Polym J 13 (6): 445

[4] Ibraheem KAK, Al-duhan JA and Himdi ST (1985)EurPolym J 21: 97

[5] Dass SC (2000), J Indian Chem Soc. 77: 69

[6] Rivas BL and Villegas SJ, Munoz C (2004)J App PolymSci 19(6): 3679-3685 


\section{$w w w . i j i e s . n e t$}

[7] Kimura H, Murata $Y$, Matsumoto A, Hasegawa K, Ohtsuka K, Fulkuda A (1999), J ApplPolymSci 74: 2273-2279

[8] Gurnule WB, Juneja HD, Paliwal LJ (2000). Ind J Chem 39: 1113-1120

[9] Rahangdale PK, Gurnule WB, Paliwal LJ, Kharat RB (2003) Synth React Inorg Met Org Chem 33: 12051212

[10] Katsutoshi N, Toshio K, Takeochuichi B, Famishisa Y, Japan JPn, KokaiTokkyo JP (1994) 08. 27: 226

[11] Eva F, Alexandra B, Hans-Josef S, Jochen E, Marlin K (2002) CA 136: 6957r

[12] Steffen K, Paul V, Hugo P, Richard VandOsselaer Tony V (2001) CA $135107732 y$

[13] Papava G, Sergeev GSW, VysokomolekulyarnyeSoedineniya (1974) 168: 18-44

[14] Shinichi N (Sumitomo Bakelite Co Japan) JPn (1996) KokaiTokkyo J P 08 143:750-770

[15] Pal $T \quad K$, Kharat $R \quad B \quad$ (1989) Die AngewMacromolChemie 173: 55-65

[16] Treavor H, Boyer PC (2007) Water Res. 40: 28762882

[17] Shah B, Shah A, Patel N (2008) Iran Polym J 17: 1732

[18] Rahangdale P K, Gurnule W B, Paliwal L J, Kharat $R$ $B$ (2003) React FunctPolym 55: 265-272

[19] Mane V D, Wahane $N J$, Gurnule W B (2009) $J$ ApplPolymSci 111: 3039-30347

[20] Tuan D F T. and Fuoss R M (1963) J PhysChem 67: 1343

[21] HugginM L (1958) Phy. Chem. High Polym John Wiley \& Sons Inc New York

[22] Krammer E O (1938) IndEngChem 30: 1200

[23] Gurnule $W$ B, Nandekar $K A$ and Dontulwar $J R$ (2012)Int J KnowlEngg3(1): 151-153

[24] Manolova N, Ignatova M, Rashkov I. (1998) Euro Polym Journal 34(8): 1133-1141

[25] Ballamy I J. $(1956,1958)$ "The IR spectra of complex molecules", Methven and Co Ltd and John-Welley and Sons INC

[26] Dyer J R, Application of Absorption Spectroscopy of Organic Compounds, $2^{\text {nd }}$ Edn. (New Delhi) Indian reprint 33-37

[27] William Kamp (1975) "Organic Spectroscopy", Mac Millan Press td Hong Kong

[28] Silverstein R M, Bassler G C and Morrill T C (1981), "SpectroIdenti Organic Comp", Jhon Wiley and Sons Inc New York 316-319

[29] Organic Chemistry (1998) Addison Westey Longman Ltd England First ISE Reprint

[30] Azarudeen $R$ S, Burkanudeen $A R$ (2012) Res ChemIntermed 38: 2155-2173

[31] DeGeso R C, Donaruma L G, Tomic E A (1962) Anal Chem 34: 845-856
[32] Gregor H P, Tasfer M, Cilardl E I, Becker (1952) IndEngChem 44: 2834-2842

[33] Pal $T \quad K$ and Kharat $R \quad B \quad$ (1989) Die AngewMakromolChem 177: 55

[34] Kapadia M, Patel M and Joshi J (2008) Iran Polym J 17(10):767-779

[35] Joshi J D, Patel NB and Patel S D (2006) Iran Polym Journal 15(3): 219-226

[36] Rahangdale S S, Gurnule W B, Zade A B (2009) Ind J Chem48A 